\title{
Explaining Cross-Cohort Differences in Life Cycle Earnings *
}

\author{
Yu-Chien Kong ${ }^{\dagger}$ \\ B. Ravikumar $\ddagger$ \\ La Trobe University \\ Federal Reserve Bank of St. Louis \\ Guillaume Vandenbroucke ${ }^{\S}$ \\ Federal Reserve Bank of St. Louis
}

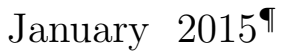

\begin{abstract}
Earnings growth has been systematically decreasing from one cohort to the next, starting with the cohort that was 25-year-old in 1940. This cohort's labor earnings were multiplied by a factor of 4 between the ages of 25 and 55. For the 1980 cohort the same calculation yields a factor of 2.2. Why are recent cohorts facing flatter earnings profiles? Our theory combines two points: (1) the incentives to accumulate human capital over one's work life are decreasing in the initial stock of human capital; (2) recent cohorts are more educated and do start their work lives with more human capital. We build and calibrate a parsimonious model of schooling and human capital accumulation on the job to fit the earnings of the 1940 cohort at different ages. Our model accounts for more than $60 \%$ of the decline in the growth rate of earnings between the 1940 and the 1980 cohorts as the result of a single exogenous factor: increasing aggregate productivity.
\end{abstract}

\footnotetext{
${ }^{*}$ We thank participants at the 2014 SED meetings, as well as Lance Lochner for useful comments. The views expressed in this article are those of the authors and do not necessarily reflect the views of the Federal Reserve Bank of St. Louis or the Federal Reserve System.

${ }^{\dagger}$ School of Economics, La Trobe University, Victoria 3086 Australia. Email: Yu-Chien.Kong@latrobe.edu.au

${ }^{\ddagger}$ Research Division, Federal Reserve Bank of St. Louis, P.O. Box 442, St. Louis, MO 63166, USA. Email: b.ravikumar@wustl.edu

${ }^{\S}$ Corresponding author. Research Division, Federal Reserve Bank of St. Louis, P.O. Box 442, St. Louis, MO 63166, USA. Email: guillaumevdb@gmail.com.

`First version: February 2014.
} 


\section{Introduction}

The labor earnings of male workers reaching their 25th birthday in 1940 were multiplied by a factor of 3.9 by the time they reached age 55 . This amounted to a 4.5 percent annual rate of growth over the course of their working lives. In contrast, the labor earnings of male workers reaching their 25 th birthday in 1980 were multiplied by a factor of 2.2. A 2.6 percent annual rate of growth. Figure 1 illustrates how systematic the decline of earnings growth was across cohorts. It also shows that the phenomenon remains even when the data is disaggregated by education level. ${ }^{1}$

To gauge the magnitude of this flattening contemplate Figure 2. It shows the earnings of 25 year old and 55 year old individuals at different points in time. The red and green circles show actual earnings. The diamonds show the earnings that 55 year old would have received each year if each cohort had experienced the age-specific earnings growth, after age 25, of the 1940 cohort. Focus on the two cohorts reaching age 25 in 1940 and in 1980 . Their earnings at 25 were $\$ 16,000$ and $\$ 32,000$ (in 2010 dollars), respectively. A factor 2 difference. But, by age 55 (in 1970 and 2010) their earnings were $\$ 64,000$ and $\$ 71,000$. A factor 1.1 difference. If the 1980 cohort had experienced the same age-specific earnings growth as the 1940 cohort, its age-55 earnings would have been $\$ 125,000$ instead of $\$ 71,000 .^{2}$

The flattening of earnings profiles has important implications for the evolution of inequality over time. This is evident from an inspection of Figure 2. Consider the year 1980. The earnings inequality between 25 and 55 year old can be read vertically as the difference between the two circles: a factor of 2. If, however, their had been no flattening of earning profiles, the 55 year old in 1980 would have experienced higher earnings and the inequality would have been a factor of almost 3.

What, then, explains the flattening of earnings profile across cohorts? We propose an answer

\footnotetext{
${ }^{1}$ Using a finer grid to distinguish more education levels does not alter this observation. Thus changes in the educational composition of the labor force are not primarily responsible for this flattening of labor earnings paths.

${ }^{2}$ We do not draw implications for the well-being of successive cohorts from these observations. The fact that latter cohorts experienced less earnings growth does not mean that they had less lifetime income since their earnings were higher.
} 
based on cross-cohort differences in schooling and human capital accumulation. The gist of our argument can be summarized in two propositions. First, members of the most recent cohorts are more educated, as indicated by their higher educational attainment and, therefore, they start their work lives with more initial human capital. Second, the incentives to accumulate human capital over one's work life are decreasing in the initial stock of human capital. Thus, members of the most recent cohorts accumulate less human capital over their working lives and, consequently, experience less earnings growth.

To evaluate the quantitative relevance of our theory we develop a parsimonious model of college attainment and human capital accumulation on the job. We borrow from the literature, e.g. BenPorath (1967), Huggett et al. (2006, 2011) and Manuelli and Seshadri (2014) to model human capital accumulation on the job. Each period a worker can allocate his time and existing stock of human capital between the production of goods and the accumulation of more human capital. The latter activity is subject to decreasing returns. An implication of the Ben-Porath model is that the returns to human capital accumulation are decreasing in the initial stock of human capital. To model college attainment we assume that all individuals are endowed with a high-school education, but that they differ in their ability to acquire human capital in college and on the job. We assume that an individual's human capital after college depends on ability, the time spent in college, and goods spending on college -a "quality" component of college education.

In our model there is only one exogenous variable responsible for both the flattening of earnings profiles and the increase in educational attainment: aggregate productivity or, equivalently, the rental rate of human capital. We assume that it grows at a constant rate. To understand how such growth generates the flattening of earnings profile across cohorts observe, first, that the most recent cohorts start their lives facing higher productivity than older cohorts. This is the key, and only, difference between cohorts. In each cohort there is a threshold level of ability such that individuals with higher ability optimally choose a college education, while the others do not. As productivity increases from one cohort to the next, and the goods used to obtain a college education become cheaper, this threshold decreases, i.e. educational attainment rises. In this context, a few 
mechanisms operate. (1) Consider a level of ability such that it is optimal to attend college at both low (old cohort) and high (recent cohort) productivity. Such individuals acquire more human capital in college in the recent cohort because goods are cheaper. Therefore, they have more out-of-college human capital and lower subsequent accumulation and earnings growth during their work lives. (2) The average college-educated worker in the recent cohort has lower ability than his counterpart in the old cohort. This follows from the fact that, as aggregate productivity rises, individuals with ability too low to initially choose college now find it optimal. Thus, the "new" college educated workers in the recent cohort are the least able while, in the old cohort they would have bee the most able high school-educated workers. This composition effect has two implications with opposite consequences on the slope of earning profiles. On the one hand ability drives human capital accumulation on the job, hence the lower average ability of college-educated workers in the new cohort tends to make their earning profile flatter than in the old cohort. On the other hand, lower ability also implies less out-of-college human capital which promotes faster accumulation and earnings growth for the recent cohort. Which one of the these mechanisms dominate is a quantitative question that we tackle in the empirical section of the paper. (3) Consider now an ability such that college is not optimal in both the old and recent cohorts. By assumption, individuals with such ability start working with exactly the same human capital in each cohort, and thus experience the same earnings growth. (4) Finally, the composition of high school-educated workers changes in the recent cohort because of the mechanism mentioned in point 2 . The average high school educated worker is of lower ability in the recent cohort. This, again, has two opposing effects on the slope of earnings profiles and, therefore, a quantitative analysis is warranted.

Practically, we calibrate our model to match some key statistics summarizing the educational attainment and life cycle earning profiles of the 1940 cohort. We then compute the optimal decisions of subsequent cohorts and compare the evolutions of life cycle earnings for these cohorts to U.S. data. We find that the model can account for 60.8 percent of the observed decline in earnings growth between the 1940 and the 1980 cohorts. We also find that the model accounts for 45 percent of the observed flattening of the high school profile and 75.3 percent for the college profiles. 
We note that, even though our model's focus is on college versus non-college educated workers, our theory does not rely on this particular partitioning of education choices. The critical observation is that individuals from more recent cohorts receive more schooling than their counterparts in older cohorts and that, therefore, they accumulate human capital at a slower pace over their work lives. We focus on the college and non-college distinction as a device to illustrate the quantitative importance of the forces at work.

\section{The Model}

In this section we describe the economic environment, and the optimization problem of an individual. We proceed to discuss the characteristics of the optimal solution for schooling and human capital accumulation on the job, and how they affect earnings growth.

\subsection{The Environment}

Time is discrete. The economy is populated by overlapping cohorts of individuals. A mass one of individuals are born each period, and live for $J$ periods. They are differentiated by their ability to accumulate human capital, which we denote $a$. The ability remains constant throughout their lives. We assume that $a \geq 0$ and that its cumulative distribution function, $A$, is time invariant. Individuals also differ in their initial, that is age-1, endowment of human capital. An individual's initial human capital depends upon his ability. Thus, we denote initial human capital by $h_{1}(a)$ for an age-1 individual with ability $a$.

Individuals can accumulate human capital through education and on the job. We consider two levels of educational attainment: high school and college. All age-1 individuals are endowed with a high school education, but they can choose whether to attend college, or not. Thus, we interpret an individual's initial human capital, $h_{1}(a)$, as human capital obtained from high school. The cost of attending college is twofold. There is a time cost since individuals attending college do not work for $s$ periods. There is also a good cost since individuals can choose the quality of their college 
education by investing goods into it. ${ }^{3}$ Individuals who do not attend college start working at age 1. Working individuals can choose, each period, to allocate their time between renting their human capital for an exogenous rate $w$, and accumulating more human capital.

The technology for accumulating human capital in college is described by the function $G\left(k, h_{1}(a), a\right)$, where $k$ stands for goods invested in college education. Thus, $G\left(k, h_{1}(a), a\right)$ is the human capital at age $s+1$, that is after $s$ periods of college, for an individual of ability $a$ with initial human capital $h_{1}(a)$ who invested $k$ units of goods (in present value) in college education.

The technology for accumulating human capital on the job is described by the function $F(n h, a)$, where $n$ stands for time spent in human capital accumulation, and $h$ for human capital at the beginning of a period. Thus, $F(n h, a)$ is the flow of additional human capital for a working individual of ability $a$ who started the period with human capital $h$ and decided to spend $n \in(0,1]$ units of time accumulating new human capital. Note that one input in this technology is a unit of human capital-time, $n h$. This is a standard assumption in the literature, e.g. Huggett et al. (2006, 2011), and Manuelli and Seshadri (2014). Heckman et al. (1998) estimate production functions for human capital where they allow the elasticities with respect to time and human capital to differ. They cannot reject the hypothesis that these elasticities are the same, however.

The rental rate for human capital, $w$, grows at the (gross) rate $g$ each period. We emphasize that $w$ is the only exogenous variable in the model. Furthermore, since $w$ is a deterministic function of time, we use it to index cohorts. We assume that human capital depreciates at rate $\delta \in(0,1)$ on the job. Finally, individuals have access to a perfect credit market where they can freely borrow and lend any amount at the (gross) rate $r$.

\footnotetext{
${ }^{3}$ Similar approaches to modeling human capital formation can be found in Erosa et al. (2010), Cordoba and Ripoll (2013), Restuccia and Vandenbroucke (2013a,b, 2014) and Manuelli and Seshadri (2014).
} 


\subsection{An Individual's Optimization Problem}

Let $W_{j}(h, w, a)$ denote the present value of earnings for a working individual of age $j$ with human capital $h$, ability $a$, and observing a wage rate $w$ in the current period:

$$
\begin{aligned}
W_{j}(h, w, a)= & \max _{n \in[0,1]} w h(1-n)+\frac{1}{r} W_{j+1}\left(h^{\prime}, w g, a\right) \\
\text { s.t } \quad & h^{\prime}=(1-\delta) h+F(n h, a) \\
& W_{J+1}=0
\end{aligned}
$$

Equation (2) describes the law of motion of human capital, and Equation (3) is a boundary condition.

Let $V^{i}(a, w)$ where $i \in\{\mathrm{hs}, \mathrm{col}\}$, denote the present value of earnings at age 1 net of the cost of education for an individual with ability $a$, observing a wage rate $w$ in the current period. The value of not attending college is thus,

$$
V^{\mathrm{hs}}(a, w)=W_{1}\left(h_{1}(a), w, a\right)
$$

that is, it is the value of starting to work at age 1 with one's initial human capital $h_{1}(a)$. The value of attending college is

$$
V^{\mathrm{col}}(a, w)=\max _{k} \frac{1}{r^{s}} W_{s+1}\left(G\left(k, h_{1}(a), a\right), w g^{s}, a\right)-k .
$$

In this problem the time cost of a college education transpires through (1) the fact that labor income is earned from age $s+1$ onward, hence the discounting term $1 / r^{s}$; and (2) the shorter working life relative to a high school-educated worker, hence the use of $W_{s+1}$ to measure the present value of labor earnings. The good cost of a college education is measured in present value by $k$. To sum up, the value of attending college is the value of starting to work at age $s+1$ with human capital $G\left(k, h_{1}(a), a\right)$ net of the good cost $k$. The decision of whether to attend college or start working at 
age 1 is determined by the solution of

$$
\max _{\text {hs,col }}\left\{V^{\mathrm{hs}}(a, w), V^{\mathrm{col}}(a, w)\right\} .
$$

\subsection{Functional Forms}

We assume that ability is log-normally distributed in each cohort,

$$
\ln a \sim N(\mu, \sigma)
$$

and that an individual's high-school human capital, $h_{1}(a)$, depends upon ability according to

$$
h_{1}(a)=z_{H} a,
$$

where $z_{H}$ is a positive parameter. We model the human capital technology in college, $G$, as

$$
G\left(k, h_{1}(a), a\right)=\left(z_{G} k\right)^{\eta}\left(a h_{1}(a)\right)^{1-\eta}
$$

where $\eta \in(0,1)$ and $z_{G}$ a scale parameter. For the human capital technology on the job, $F$, we use the following specification:

$$
F(n h, a)=z_{F} a(n h)^{\phi}
$$

where $\phi \in(0,1)$ and $z_{F}$ is a scale parameter.

\subsection{Discussion}

We now discuss the determinants of earnings growth. First, we analyze the on-the-job human capital accumulation problem and establish that, conditional on ability, an individual's earnings growth is determined by its out-of-school stock of human capital. Second, we discuss the schooling decision and the determination of the out-of-school stock of human capital. 


\subsection{Working Life}

We show, in appendix B, that problem (1)-(3) admits an interior solution of the form

$$
W_{j}(h, w, a)=\beta_{j}(w) h+\alpha_{j}(w, a)
$$

where

$$
\beta_{j}(w)=w\left[\frac{1-\chi^{J-j+1}}{1-\chi}\right]
$$

and $\chi \equiv(1-\delta) g / r$. We focus the discussion on this interior solution. ${ }^{4}$ We interpret $\beta_{j}(w)$ as the marginal return to human capital, that is the increase in the present value of income resulting from a marginal increase in the stock of human capital. Note that $\beta_{j}(w)$ is decreasing in age. That is, the marginal return to human capital is lower as an individual's time horizon becomes shorter. Second, $\beta_{j}(w)$ is proportional to $w$. That is, the marginal return to human capital is proportional to its rental rate, and the coefficient of proportionality depends upon age. Finally, observe that $\beta_{j}(w)$ is independent of ability.

Using Equation (8) the first order condition for the optimal choice of $n h$, the human capital-time devoted to human capital accumulation, reads

$$
w=\frac{1}{r} \beta_{j+1}(w g) F_{1}(n h, a)
$$

The left-hand side of this equation is the marginal cost of allocating human capital-time to accumulating more human capital, i.e. the forgone earnings, $w$. The right-hand side is the marginal benefit, i.e. the discounted marginal increase in wealth. It comprises two parts: the marginal value of human capital in the next period, measured by $\beta_{j+1}(w g)$, and the marginal increase in human capital, measured by the marginal product of $n h$, that is $F_{1}(n h, a)$.

\footnotetext{
${ }^{4}$ In a corner, that is when the optimal $n$ is 1 , the value function is $W_{j}(h, w, a)=\frac{1}{r} W_{j+1}((1-\delta) h+F(h, a), w g, a)$.
} 
Given the functional form for $F$, Equation (9) yields the following interior solution for $n$ :

$$
n=\frac{1}{h}\left[\frac{a z_{F} \phi}{r} \frac{\beta_{j+1}(w g)}{w}\right]^{1 /(1-\phi)}
$$

which shows that the time spent in human capital accumulation is increasing in ability, and decreasing in the current stock of human capital. As is common in frameworks such as this one (e.g. Manuelli and Seshadri (2014) or Huggett et al. (2006)) a corner solution may prevail where $n=1$ for individuals with low human capital and/or high ability since, in both cases, the return to time spent in human capital accumulation is high. Thus, the typical time path of $n$ is weakly decreasing with age: if the initial human capital is low enough, the individual spends some periods using all his time in human capital accumulation. Then, as human capital accumulates, less time is devoted to accumulating more. Figure 3 illustrates the typical path of $n$.

Equation (10) implies that the human capital-time spent in human capital accumulation, $n h$, is independent of the productivity, $w$. This is because, on the one hand an increase in $w$ raises the returns to human capital (measured by $\beta_{j+1}(w g)$ ) while, on the other hand, it increases the opportunity cost of time spent accumulating human capital (measured by $w$ ). The linearity of $\beta_{j}$ implies that these effects exactly offset each others.

What then determines earnings growth over the life cycle? More specifically, what are the factors affecting earnings growth differently from one cohort to the next? The earnings of an individual at any point in time are given by $w h(1-n)$. Thus, the growth rate of $w$ is a determinant of earnings growth. In our experiment, however, this rate is the same for all cohorts by assumption. It is, therefore, not the source of any changes across cohorts. The second driver of earnings growth is the term $h(1-n)$. Its growth rate is an average of the growth rate of $h$ and the growth rate of $n h$. As established above, the latter is independent of $w$ and depends solely upon age. Since $w$ is the only variable that differentiates cohorts, the growth rate of $n h$ does not differ from one cohort to the next. That is, conditional on age, the growth rate of $n h$ is the same across all cohorts. Turn finally to $h$, the stock of human capital itself. Combining Equations (2) and (10) reveals that its 
rate of growth is

$$
\frac{h_{j+1}}{h_{j}}=1-\delta+\frac{z_{F} a}{h_{j}}\left[\frac{a z_{F} \phi}{r} \frac{\beta_{j+1}(w g)}{w}\right]^{\phi /(1-\phi)} .
$$

Since, again, the term $\beta_{j+1}(w g) / w$ is independent of $w$, the growth rate of $h$ over the life cycle is independent of $w$. Importantly, however, it is a decreasing function of the initial stock of human capital, $h_{j}$, and an increasing function of ability. The typical path of human capital over the life cycle is illustrated in Figure 4: when an individual starts with high human capital, the growth rate of human capital, and therefore earnings, is lower.

Equation (11) illustrates some of the main mechanisms at work in our model. Assume for the moment that individuals from the most recent cohort start working with more human capital than individuals from an older cohort. Then, conditional on ability, each individual accumulates human capital at a slower pace in the recent cohort. This implies flatter earning profiles for this cohort. In addition, Equation (11) reveals that earnings profiles are flatter for individuals with lower ability, holding the initial level of human capital constant.

We have established that, conditional on ability, the out-of-school stock of human capital is the only determinant of lifetime earnings growth. We now turn to the determination of this out-of-school stock, which depends upon the schooling decision of individuals.

\subsection{Schooling choice}

The present value of income for an individual who decides to start working after high-school is, using Equation (4),

$$
V^{\mathrm{hs}}(a, w)=\beta_{1}(w) h_{1}(a)+\alpha_{1}(w, a) .
$$

The value of going to college is, using Equation (5),

$$
V^{\mathrm{col}}(a, w)=\max _{k} \frac{1}{r^{s}}\left[\beta_{s+1}\left(w g^{s}\right) G\left(k, h_{1}(a), a\right)+\alpha_{s+1}\left(w g^{s}, a\right)\right]-k .
$$


The first order condition for $k$ is

$$
1=\frac{1}{r^{s}} \beta_{s+1}\left(w g^{s}\right) G_{1}\left(k, h_{1}(a), a\right)
$$

which equates the marginal good cost of a college education with its marginal returns. The former is one while the latter results from the marginal productivity of goods in the college human capital technology, $G_{1}\left(k, h_{1}(a), a\right)$, and the marginal return to human capital at the end of the college period, $\beta_{s+1}\left(w g^{s}\right)$. Given the functional form for $G$ we find that, at the solution $k^{*}$ of problem (5), the out-of-college human capital is:

$$
G\left(k^{*}, h_{1}(a), a\right)=a h_{1}(a)\left[\frac{\eta z_{G}}{r^{s}} \beta_{s+1}\left(w g^{s}\right)\right]^{1 /(1-\eta)} .
$$

Note that more able individuals accumulate more human capital in college. There are, therefore, two counteracting effects of ability on earnings growth. On the one hand, individuals with high ability start working with more human capital. This tends to reduce earnings growth later in life, as established in the previous section. On the other hand, these individuals accumulate human capital faster when they work - this also was established in the previous section. This tends to increase their earnings growth later in life. Which one of these two effects dominates is a quantitative question that we address in the next section.

Equation (13) shows that the out-of-college stock of human capital is increasing in the level of productivity, $w$. This is because the marginal cost of a good invested in a college education is constant and equal to 1, while the marginal benefit depends upon the marginal return to human capital, $\beta_{s+1}\left(w g^{s}\right)$, which is increasing in $w$. This feature of the solution implies that, conditional on ability and a college education, an individual starts working with more human capital when the level of productivity is higher. It follows then, from the discussion in the previous section, that such an individual experiences less earnings growth.

To determine the educational attainment of a given cohort we compute the threshold ability level such that an individual with this ability is indifferent between attending college or not, that is we 
find $a$ such that

$$
V^{\mathrm{col}}(a, w)=V^{\mathrm{hs}}(a, w)
$$

We show in appendix C.3 that this equation can be written as

$$
a^{\phi /(1-\phi)} Z_{1}+Z_{2}=a w^{\eta /(1-\eta)} Z_{3}
$$

where $Z_{1}, Z_{2}$ and $Z_{3}$ are positive constant. We now describe the case where the left-hand side of Equation (14) is convex, since this is the relevant case in our quantitative exercise, i.e., $\phi>0.5$. Panel A of Figure 5 describes the determination of educational attainment, that is the solution of Equation (14).

The first observation is that when the wage rate is too low Equation (14) may not have a solution. The returns to human capital can be so low that no individual finds it profitable to spend $s$ periods in college, instead of starting to work right-away. College enrollment would then be zero.

For higher levels of the wage rate, as represented in Panel A of Figure 5, there are two ability thresholds, $a^{*}(w)$ and $a^{* *}(w)$, at which individuals are indifferent between college and high school. The schooling choice of an individual with ability $a$ facing productivity $w$ at age 1 is then

$$
\begin{cases}\text { Attend college if } & a \in\left(a^{*}(w), a^{* *}(w)\right) \\ \text { Do not attend college if } & a \notin\left(a^{*}(w), a^{* *}(w)\right)\end{cases}
$$

The reason why individuals with ability less than $a^{*}(w)$ do not attend college is because their ability to accumulate human capital in college and after is not high enough to offset the opportunity cost of college. The reason why individuals with very high ability, that is above $a^{* *}(w)$, do not attend college is because their ability is so high that accumulating human capital on the job is more profitable than attending college and foregoing earnings for $s$ periods.

An inspection of Equation (14) also reveals the effect of an increase in productivity on the educational attainment of different cohorts. Consider an "old" and a "recent" cohort. Since productivity 
is growing, its level is lower when the "old" cohort starts its life than when the "recent" cohort starts its life. Label these productivity levels $w_{\text {old }}$ and $w_{\text {recent }}$, respectively. Panel B of Figure 5 shows the effect of this difference on the educational attainment of the two cohorts. It transpires that facing a higher level of productivity at the start of their lives induce more people to attend college in the recent cohort than in the old one.

In our quantitative section, the fraction of individuals above $a^{* *}$ is negligible at every point in time. Thus, from now on, we abstract from this term to simplify the discussion and the notations. The decline in $a^{*}$ induced by the growth in productivity means that ability levels below, but close to, $a^{*}\left(w_{\text {old }}\right)$ will find it optimal to attend college when productivity rises to $w_{\text {recent }}$. This implies that (1) the average college-educated worker has lower ability in the recent cohort since the new college-educated have the lowest ability; and (2) the average high school-educated worker also has lower ability since only the least able individuals remain high school-educated as productivity rises.

\section{The Quantitative Exercise}

\subsection{Calibration}

We assume that a model period is 1 year and that individuals live for $J=50$ periods (from 18 to 68). College lasts for four periods, thus $s=4$, and we set the annual rate of interest to $5 \%$, thus $r=1.05$. We follow Huggett et al. (2006) and set the annual rate of depreciation of human capital at $1.14 \%$, thus $\delta=1.14 / 100$.

The remaining parameters are $\theta \equiv\left(\mu, \sigma, \eta, \phi, z_{H}, z_{G}, z_{F}, g\right)^{\prime}$. We calibrate them by minimizing a distance between moments simulated from the model, and their empirical counterparts. Specifically, we compute a series of wages growing through time at rate $g$. We denote by $w_{\tau}(\theta)$ the wage rate in calendar year $\tau$, and adopt the normalization $w_{1940}(\theta)=1$. We then compute the optimal decisions of individuals reaching age 25 in the calendar years $\tau=1940,1950, \ldots, 1980$. We call an individual reaching age 25 in calendar year $\tau$ a member of cohort $\tau$. 
We let $p_{\tau}(\theta)$ denote the proportion of individuals from cohort $\tau$ who optimally decide to attend college:

$$
p_{\tau}(\theta)=\int_{a^{*}\left(w_{\tau}(\theta)\right)} A^{\prime}(\theta) d a .
$$

Note that $p_{\tau}(\theta)$ depends upon our choice of $\theta$ via two channels. First the growth rate of productivity, $g$, determines the level of wages $w_{\tau}(\theta)$ which, in turn, determines the critical ability $a^{*}\left(w_{\tau}(\theta)\right)$. Second, given $a^{*}\left(w_{\tau}(\theta)\right)$, the mass of college educated workers of cohort $\tau$ depends on the density function $A^{\prime}$, which is determined by the parameters $\mu$ and $\sigma$. We denote by $E_{\tau, j}^{i}(\theta)$ the average earnings for cohort $\tau$ at age $j$, conditional on educational attainment $i \in\{\mathrm{hs}, \mathrm{col}\}$. We also define the conditional standard deviation $S_{\tau, j}^{i}(\theta) .{ }^{5}$ Let $\mathbf{E}_{\tau, j}^{i}$ and $\mathbf{S}_{\tau, j}^{i}$ denote their empirical counterparts. We find $\theta$ by solving the following problem:

$$
\begin{aligned}
\min _{\theta} \sum_{i \in\{\mathrm{hs}, \mathrm{co}\}} \sum_{j=35,45,55} & \left(\frac{E_{1940, j}^{i}(\theta) / E_{1940,25}^{i}(\theta)}{\mathbf{E}_{1940, j}^{i} / \mathbf{E}_{1940,25}^{i}}-1\right)^{2} \\
& +\sum_{i \in\{\mathrm{hs}, \mathrm{co}\}} \sum_{j=25,35,45,55}\left(\frac{S_{1940, j}^{i}(\theta) / E_{1940, j}^{i}(\theta)}{\mathbf{S}_{1940, j}^{i} / \mathbf{E}_{1940, j}^{i}}-1\right)^{2} \\
& +\sum_{\tau=1940, \ldots, 1980}\left(p_{\tau}(\theta) / \mathbf{p}_{\tau}-1\right)^{2} .
\end{aligned}
$$

There are three parts in this objective function. The first part indicates that we calibrate our model to match the growth of earnings experienced by the 1940 cohort in the data, for high school and college educated workers. The second part indicates that we calibrate our model to the dispersion (measured by the coefficient of variation) of earnings for the 1940 cohort, at different point in its life cycle, for high school and college educated workers. The last part of the objective function implies that we calibrate the model to match the educational attainment of successive cohorts of workers, from 1940 to 1980.

Note that in minimization problem (15) the earnings data pertain only to the 1940 cohort. The earnings growth of this cohort is informative to discipline parameters such as the growth rate $g$, and

\footnotetext{
${ }^{5}$ Both $E_{\tau, j}^{i}(\theta)$ and $S_{\tau, j}^{i}(\theta)$ are computed by integrating earnings over the distribution of types. Details are provided in Appendix D.
} 
the parameters determining the pace of human capital accumulation on the job: the mean ability, $\mu$, and the parameters of the production function $F: z_{F}$ and $\phi$. Remember, in addition, that our theory ascribes differences in earnings growth to the stock of human capital at the beginning of one's work life. Thus, the data on earnings growth for high school and college workers also discipline the parameters governing the initial human capital of the high school workers, $z_{H}$, and the production function for human capital in college, $z_{G}$ and $\eta$. The second part of the objective function disciplines, among others parameters, the dispersion in ability, $\sigma$. The last part of the objective function is the only place where time series information is used. We calibrate the model to match the time path of educational attainment for each cohort because it imposes additional discipline on the distribution of ability given the growth in earnings. Furthermore, matching the educational attainment of successive cohorts allows us to assess the quantitative relevance of the composition effect leading to the flattening of earnings profiles.

Table 2 reports the calibrated values of the parameters, and Figure 6 shows the model's fit to the data. We find $\phi=0.63$ for the elasticity parameter in the production function for human capital on the job. This is comparable to existing estimates of this parameter. Namely, Browning et al. (1999) report a range of estimates, varying from 0.5 to 1 in the literature. Note that the growth rate of productivity, $g$, is 0.5 percent per year. This is noticeably less than the targeted growth rate of labor earnings over the work life of the 1940 cohort: 4.7 and 4 percent for college- and high school-educated workers, respectively. This difference shows that most of earnings growth in our model is endogenous, and determined by human capital accumulation.

\subsection{Discussion}

Figure 7 illustrates some aspects of the economy of the model. Panel A shows the level of human capital at age 25 , by ability and education level. The vertical line labelled $a^{*}\left(w_{1940}(\theta)\right)$ is the threshold for college attendance in the 1940 cohort. Thus, points to the left of the threshold represent high school-educated workers while points to the right represent college-educated workers. Not surprisingly, the most able individuals have the most human capital. Note the discontinuity at 
$a^{*}\left(w_{1940}(\theta)\right)$. It indicates how much more human capital the marginal individual has accumulated by age 25 , as a result of having attended college instead of resorting to accumulation on the job only.

Turn now to panel B. It shows the growth in human capital, between 25 and 55, for each individual. The most able increase their human capital the fastest. The discontinuity at $a^{*}\left(w_{1940}(\theta)\right)$ indicates, however, that the marginal worker increases his human capital less when he attends college than when he does not. This is a key mechanism in our model, which we discussed in the previous section. It results from the fact that the marginal individual has more human capital at age 25 (see panel A) if he attends college. This higher stock at age 25 implies, in turn, a lower rate of accumulation in the subsequent years.

The fact, observed on Panel B, that the pace of human capital accumulation over life is increasing in an individual's ability deserve further comments. Consider Equation (11) again. It shows that human capital growth is increasing in ability and decreasing in the initial stock of human capital. Thus Panel A and Panel B of Figure 7 show that, even though the most able individuals start working with more human capital (Panel A) they do experience faster accumulation because of their abilities.

Panel $\mathrm{C}$ shows earnings growth between age 25 and age 55. Earnings growth is the highest for the most able individuals, with a discontinuity at the marginal college worker which is a direct effect of the discontinuity in Panel B. Because of this discontinuity some college-educated workers experience less earnings growth than some high school-educated workers. In the data, however, earnings growth is higher for college-educated workers -see Figure 1. In order to reconcile Figure 7-C with this observation, the appropriate distribution of type must be used, hence our choice of using earnings growth for college- and high school-workers as a way to discipline the parameters of the model. 


\subsection{Main Experiment}

We use our model to compute sequences of schooling and human capital accumulation decisions for a sequence of cohorts from 1940 to 1980. Specifically we first discretize the distribution of ability, $a$, on a 200-point grid. We then let productivity, $w$, grow at the rate $g$ given in Table 2. Thus, each cohort differs from the others in only one dimension: the level of productivity it faces at age 1. For each cohort we compute the optimal schooling decisions, time spent in human capital accumulation, human capital stock and earnings for each one of the 200 ability levels in the grid.

To understand our results, Figure 8 compares the decisions of the 1940 and 1980 cohorts. Panel A shows the level of human capital at age 25. We distinguish three groups of ability. The "alwayshigh school" group, with $a \leq a^{*}\left(w_{1980}(\theta)\right)$, corresponds to those who decide to start working at age 1 under both levels of productivity. The "switcher," with $a^{*}\left(w_{1980}(\theta)\right) \leq a \leq a^{*}\left(w_{1940}(\theta)\right)$ are those that are prompted to attend college by the increase in productivity. The "always-college" group, with $a \geq a^{*}\left(w_{1940}(\theta)\right)$, corresponds to those who attend college under both the low and high productivity levels. Panel A reveals that the human capital at age 25 in the "always-high school"group is the same in each cohort. This is because their human capital out of high school is exogenously given, and accumulation on the job is independent of productivity -see Equation (11). Panel A also reveals that human capital at age 25 is higher for each member of the "switcher" and the "always-college" groups. This is the result of college attendance. For the "switcher" group this is because attending college allows them to start working with more human capital than if they had not gone to college. For the "always-college" group this is because they accumulate more human capital in college as a result of the higher level of productivity -see Equation (13). Panel B shows the effect of productivity growth on the pace of human capital accumulation: those having more human capital at age 25 , as a result of the increase in productivity, accumulate human capital at a slower rate between 25 and 55 .

Panel C shows the effect of productivity on earnings growth. They decrease for individuals having more human capital at age 25. Panel $\mathrm{C}$ also exemplifies the two mechanisms are at work in the 
model. There is a "direct" effect of productivity growth on those ability levels that are induced to accumulate more human capital. That is, holding ability constant, earnings growth decreases for the "switcher" and the "always-college" group. There is also a composition effect since the ability composition of each group changes. For the "always-high school" group, the composition effect is the only effect at work. This result from our assumption that human capital out of high school is given, and independent of productivity.

Figure 9 shows the model's implications for the earnings growth of each cohort, from 1940 to 1980, and contrasts it to the data. Table 3 quantifies these findings. To read the table, consider the average worker in the 1940 cohort. Its earnings are multiplied by a factor of 3.9 between the age of 25 and 55 -see Appendix A. For the 1980 cohort, the same calculation yields 2.21. Thus, earnings growth change by $2.21 / 3.9-1=-43.3 \%$. Using the same metric the model predicts that earnings growth change by $-26.3 \%$ between the 1940 and the 1980 cohort. The ratio between the model's prediction and the data, $-26.3 /-43.3=60.8 \%$, indicates the extent to which the model accounts for the decline in earnings growth for the average worker. Similar calculations reveal that the model accounts for $45 \%$ of the decline for high-school educated workers, and $75.3 \%$ of the decline for college-educated workers.

One reason why our model predicts a stronger flattening for the college- than for the high schooleducated workers is that, for high school workers, only the composition effect from the increase in educational attainment contributes to the flattening. That is, the only reason why the growth in earnings is flatter in the recent cohort of high school workers is that the ability of the average high school worker decreases in each cohort. ${ }^{6}$ We infer, from this observation, that the composition is quantitatively relevant: it accounts for $45 \%$ of the flattening for high school workers. For college educated workers an additional effect is at work: the fact that each college educated worker starts working with more human capital.

We emphasize that the only variable driving our results is the exogenous growth in productivity.

\footnotetext{
${ }^{6}$ The model predicts a $12 \%$ decline in the average ability of high school and college educated workers, between the 1940 and 1980 cohorts.
} 
As emphasized earlier, the rate of growth that we use is small: 0.5 percent per year. This is because most income growth in the model is endogenous and driven by human capital accumulation. We also note that, by construction, the growth rate of labor income in the model fits the data for the 1940 cohort. Since this is also the cohort that faces the highest income growth, we conducted the following sensitivity experiment. We computed the solution of the model with a growth rate of productivity of 0.25 percent instead of 0.5 , and left the other parameters at their values indicated in Table 2. The prediction of the model then changes along two dimensions. First, there is less flattening in the earnings profiles. In particular, the model accounts for 34.4 (instead of 60.8) percent of the drop in earnings growth of the average worker between the 1940 and 1980. Second, educational attainment increases by about half of the observed increase in the data. This means that the composition effect affecting the growth in earnings is not as strong as in the baseline model.

\section{Conclusion}

The earnings profile of workers are becoming flatter with each new cohort. In this paper, we proposed a quantitative theory of this phenomenon. We used a model of human capital accumulation on the job that is now standard in the literature, and embedded it into a schooling choice model. The model accounts for 60.8 percent of the observed flattening of earnings for the average worker, between the 1940 and the 1980 cohort. Our theory ascribes this to only one exogenous variable: aggregate productivity growth.

There are a few mechanisms generating our results. First, the standard model of human capital that we use (à la Ben Porath) implies that the higher the out-of-school stock of human capital, the lower the subsequent accumulation and earnings growth. Since the most recent cohorts accumulate more human capital in college than the older ones, they start working with more human capital and face less earnings growth. There are also composition effects at work. Namely, the increase in college attainment of successive cohorts implies that the average ability of high school- and collegeeducated workers is lower in the most recent cohort. Since ability is a determinant of human capital accumulation and earnings growth on the job, these effect reduce the slope of earnings profile for 
the recent cohorts. We found that, for high school-educated workers the composition effect alone accounts for 45 percent of the actual decline.

Our model is simple and tractable and our experiment suggests that the mechanism it emphasizes is quantitatively relevant. Other forces are certainly at works in the data. For instance, the growth rate in productivity may not be constant and there exists evidence that it declined toward the end of the 20th century -see Keller (2014). We leave the exploration of such additional mechanisms for future work. 


\section{A Data}

The data for Figures 1 are from the IPUMS-USA database. ${ }^{7}$ The earnings variable is incwage. We consider white (raced=100) male $(\mathrm{sex}=1)$ workers, employed and working for a wage (empstat $=1$, classwkr=2). We group the data by age intervals: 20-29,30-39, ., 50-59 which we label $25,35, \ldots 55$. We deflate the data using the Bureau of Labor Statistics' Consumer Price Index. To construct age profiles of earnings by cohort, we build "synthetic" cohorts. That is, we consider individuals of age 25 in 1940, age 35 in 1950, etc... and we label these groups the "1940 cohort," the "1950 cohort," etc... For education we use educ $=6$ for high school and educ $\geq 7$ for college. This means that we label as "high school-workers" individuals whose highest educational attainment is a completed high school degree. Table 1 displays earnings figures in panel A for 5 cohorts. Panel $\mathrm{B}$ presents similar statistics for an alternative definition of high school v. college. In panel B we label "high school" a worker that has at least a high school degree and up to 3 years of college, we label "college" a worker that has at least 4 years of college completed.

\section{B Human capital accumulation on the job}

The optimization problem of a worker is

$$
\begin{aligned}
W_{j}(h, w, a)= & \max _{n \in[0,1]} w h(1-n)+\frac{1}{r} W_{j+1}\left(h^{\prime}, w g, a\right) \\
\text { s.t } \quad & h^{\prime}=(1-\delta) h+F(n h, a) \\
& W_{J+1}=0
\end{aligned}
$$

It is immediate that, in the last period of life, $W_{J}(h, w, a)=w h$. Consider now age $J-1$. The optimization problem is

$$
W_{J-1}(h, w, a)=\max _{n \in[0,1]} w h(1-n)+\frac{1}{r} w g\left[(1-\delta) h+z_{F} a(n h)^{\phi}\right] .
$$

The first order condition for $n$ at an interior is $w h=r^{-1} w g z_{F} a h^{\phi} \phi n^{\phi-1}$, implying

$$
n h=\left[\frac{1}{r} g z_{F} a \phi\right]^{1 /(1-\phi)} .
$$

\footnotetext{
${ }^{7}$ Steven Ruggles, J. Trent Alexander, Katie Genadek, Ronald Goeken, Matthew B. Schroeder, and Matthew Sobek. Integrated Public Use Microdata Series: Version 5.0 [Machine-readable database]. Minneapolis: University of Minnesota, 2010.
} 
Table 1: Annual earnings (1,000 dollars of 2010) by generation, age and educational attainment

\begin{tabular}{|c|c|c|c|c|c|c|c|c|c|c|}
\hline & \multicolumn{5}{|c|}{$\mathrm{A}$} & \multicolumn{5}{|c|}{ B } \\
\hline & 25 & 35 & 45 & 55 & $55 / 25$ & 25 & 35 & 45 & 55 & $55 / 25$ \\
\hline \multicolumn{11}{|l|}{ ALL } \\
\hline 1940 & 16.49 & 32.87 & 53.26 & 64.32 & 3.90 & & & & & \\
\hline 1950 & 22.06 & 48.45 & 66.06 & 61.80 & 2.80 & & & & & \\
\hline 1960 & 29.99 & 58.30 & 61.52 & 69.01 & 2.30 & & & & & \\
\hline 1970 & 35.49 & 52.52 & 67.25 & 74.60 & 2.10 & & & & & \\
\hline 1980 & 32.08 & 53.99 & 70.57 & 70.99 & 2.21 & & & & & \\
\hline \multicolumn{11}{|c|}{ High SCHOOL } \\
\hline 1940 & 15.10 & 30.43 & 46.49 & 54.48 & 3.61 & 15.58 & 31.37 & 48.78 & 57.20 & 3.67 \\
\hline 1950 & 22.34 & 43.00 & 55.09 & 52.02 & 2.33 & 21.79 & 44.78 & 57.83 & 54.39 & 2.50 \\
\hline 1960 & 29.47 & 50.50 & 51.98 & 51.27 & 1.74 & 28.88 & 52.52 & 54.20 & 56.61 & 1.96 \\
\hline 1970 & 35.62 & 46.56 & 50.58 & 52.21 & 1.47 & 33.85 & 47.94 & 55.46 & 56.87 & 1.68 \\
\hline 1980 & 31.71 & 42.15 & 49.75 & 47.33 & 1.49 & 30.94 & 46.00 & 54.25 & 51.65 & 1.67 \\
\hline \multicolumn{11}{|c|}{ College } \\
\hline 1940 & 19.55 & 36.46 & 62.87 & 78.23 & 4.00 & 22.17 & 38.59 & 70.29 & 89.76 & 4.05 \\
\hline 1950 & 21.60 & 54.78 & 78.59 & 71.73 & 3.32 & 23.59 & 58.63 & 87.77 & 79.85 & 3.39 \\
\hline 1960 & 30.71 & 67.09 & 70.42 & 80.88 & 2.63 & 34.93 & 73.18 & 78.08 & 95.65 & 2.74 \\
\hline 1970 & 35.34 & 56.40 & 74.78 & 87.72 & 2.48 & 41.93 & 60.80 & 87.54 & 102.36 & 2.44 \\
\hline 1980 & 32.44 & 60.00 & 84.46 & 85.75 & 2.64 & 36.25 & 70.69 & 101.03 & 104.24 & 2.88 \\
\hline
\end{tabular}

Source: IPUMS and authors calculations.

Note: In panel A "High school" is defined as workers whose highest educational attainment by age 25 is a completed high school degree. In panel B "High school" is defined as workers whose educational attainment by age 25 is a completed high school degree or up to 3 years of college.

Substituting this solution into the objective function, and rearranging, yields:

$$
\begin{aligned}
W_{J-1}(h, w, a) & =\beta_{J-1}(w) h+\alpha_{J-1}(w, a) \\
\beta_{J-1}(w) & =w\left[1+\frac{g}{r}(1-\delta)\right] \\
\alpha_{J-1}(w, a) & =w \frac{1-\phi}{\phi}\left[\frac{1}{r} g z_{F} a \phi\right]^{1 /(1-\phi)} .
\end{aligned}
$$

Turn now to the generic period $j$. Using the result just derive, assume that

$$
W_{j+1}(h, w, a)=\beta_{j+1}(w) h+\alpha_{j+1}(w, a) .
$$


Then the age- $j$ problem is

$$
\begin{gathered}
W_{j}(h, w, a)=\max _{n \in[0,1]} w h(1-n)+\frac{1}{r}\left[\beta_{j+1}(w g) h^{\prime}+\alpha_{j+1}(w g ; a)\right] \\
\text { s.t. } \quad h^{\prime}=(1-\delta) h+z_{F} a(n h)^{\phi}
\end{gathered}
$$

that is

$$
W_{j}(h, w, a)=\max _{n \in[0,1]} w h(1-n)+\frac{1}{r}\left[\beta_{j+1}(w g)(1-\delta) h+\beta_{j+1}(w g) z_{F} a(n h)^{\phi}+\alpha_{j+1}(w g ; a)\right] .
$$

Using the first order condition for $n$, an interior solution is:

$$
n h=\left[\frac{1}{r} \frac{\beta_{j+1}(w g)}{w} z_{F} a \phi\right]^{1 /(1-\phi)} .
$$

Substituting into the objective function and rearranging yields:

$$
\begin{aligned}
W_{j}(h, w, a) & =\beta_{j}(w) h+\alpha_{j}(w, a) \\
\beta_{j}(w) & =w+\frac{1}{r} \beta_{j+1}(w g)(1-\delta) \\
\alpha_{j}(w, a) & =\kappa w\left[\frac{1}{r} \frac{\beta_{j+1}(w g)}{w} z_{F} a\right]^{1 /(1-\phi)}+\frac{1}{r} \alpha_{j+1}(w g ; a) \\
\kappa & =\phi^{\phi /(1-\phi)}-\phi^{1 /(1-\phi)} .
\end{aligned}
$$

These results can be simplified further by solving for $\beta_{j}$ and $\alpha_{j}$. This yields

$$
\begin{aligned}
\beta_{j}(w) & =w\left[\frac{1-\chi^{J-j+1}}{1-\chi}\right] \\
\alpha_{j}(w, a) & =a^{1 /(1-\phi)} w \Delta \sum_{\tau=j}^{J}\left(\frac{g}{r}\right)^{\tau-j}\left[\frac{1-\chi^{J-\tau}}{1-\chi}\right]^{1 /(1-\phi)}
\end{aligned}
$$

where $\chi=(1-\delta) g / r$ and $\Delta=\kappa\left[g z_{F} / r\right]^{1 /(1-\phi)}$. 


\section{The Schooling Problem}

\section{C.1 The value of high-school}

It is immediate that

$$
\begin{aligned}
V^{h s}(a) & =W_{1}\left(h_{1}(a), w, a\right) \\
& =\beta_{1}(w) h_{1}(a)+\alpha_{1}(w, a) \\
& =w\left[\frac{1-\chi^{J}}{1-\chi}\right] z_{H} a+a^{1 /(1-\phi)} w \Delta \sum_{\tau=1}^{J}\left(\frac{g}{r}\right)^{\tau-j}\left[\frac{1-\chi^{J-\tau}}{1-\chi}\right]^{1 /(1-\phi)}
\end{aligned}
$$

\section{C.2 The value of college}

The value of a college education is the solution of the following optimization problem:

$$
\max _{k} r^{-s} \beta G\left(k, h_{1}(a) ; a\right)+r^{-s} \alpha-k
$$

where $G\left(k, h_{1}(a) ; a\right)=\left(z_{G} k\right)^{\eta}\left(a h_{1}(a)\right)^{1-\eta}$. Note that, for simplifying notation, the term $\beta$ replaces $\beta_{s+1}\left(w g^{s}\right)$, and $\alpha$ replaces $\alpha_{s+1}\left(w g^{s} ; a\right)$.

The first order condition for $k$ is $r^{-s} \beta \eta z_{G}^{\eta} k^{\eta-1}\left(a h_{1}(a)\right)^{1-\eta}=1$, implying

$$
k=a h_{1}(a)\left[r^{-s} \beta \eta z_{G}^{\eta}\right]^{1 /(1-\eta)} .
$$

Substituting into the optimization problem, and rearranging, yields

$$
V^{c o l}(a, w)=\left(r^{-s}\right)^{1 /(1-\eta)} \zeta a h_{1}(a)\left[\beta_{s+1}\left(w g^{s}\right) z_{G}^{\eta}\right]^{1 /(1-\eta)}+r^{-s} \alpha_{s+1}\left(w g^{s} ; a\right)
$$

where $\zeta=\eta^{\eta /(1-\eta)}-\eta^{1 /(1-\eta)}$. This is also (using the fact that $\left.h_{1}(a)=z_{H} a\right)$ :

$$
\begin{aligned}
V^{c o}(a)=\left(r^{-s}\right)^{1 /(1-\eta)} \zeta z_{H} a^{2}\left[w g^{s}\left[\frac{1-\chi^{J-s}}{1-\chi}\right] z_{G}^{\eta}\right]^{1 /(1-\eta)} & \\
& \quad+r^{-s} a^{1 /(1-\phi)} w g^{s} \Delta \sum_{\tau=s+1}^{J}\left(\frac{g}{r}\right)^{\tau-s+1}\left[\frac{1-\chi^{J-\tau}}{1-\chi}\right]^{1 /(1-\phi)}
\end{aligned}
$$




\section{C.3 The optimal choice}

Equating the value of college and high-school

$$
\begin{aligned}
w\left[\frac{1-\chi^{J}}{1-\chi}\right] z_{H} a+a^{1 /(1-\phi)} w C \sum_{\tau=1}^{J}\left(\frac{g}{r}\right)^{\tau-1} & {\left[\frac{1-\chi^{J-\tau}}{1-\chi}\right]^{1 /(1-\phi)}=} \\
\left(r^{-s}\right)^{1 /(1-\eta)} \zeta z_{H} a^{2}\left[w g^{s}\left[\frac{1-\chi^{J-s}}{1-\chi}\right] z_{G}^{\eta}\right]^{1 /(1-\eta)}+ & r^{-s} a^{1 /(1-\phi)} w g^{s} \Delta \sum_{\tau=s+1}^{J}\left(\frac{g}{r}\right)^{\tau-s+1}\left[\frac{1-\chi^{J-\tau}}{1-\chi}\right]^{1 /(1-\phi)}
\end{aligned}
$$

or

$$
a^{\phi /(1-\phi)} Z_{1}+Z_{2}=a w^{\eta /(1-\eta)} Z_{3}
$$

where

$$
\begin{aligned}
& Z_{1}=\Delta \sum_{\tau=1}^{J}\left(\frac{g}{r}\right)^{\tau-1}\left[\frac{1-\chi^{J-\tau}}{1-\chi}\right]^{1 /(1-\phi)}-r^{-s} g^{s} \Delta \sum_{\tau=s+1}^{J}\left(\frac{g}{r}\right)^{\tau-s-1}\left[\frac{1-\chi^{J-\tau}}{1-\chi}\right]^{1 /(1-\phi)}>0, \\
& Z_{2}=\left[\frac{1-\chi^{J}}{1-\chi}\right] z_{H}>0 \\
& Z_{3}=\left(r^{-s}\right)^{1 /(1-\eta)} \zeta z_{H}\left[g^{s}\left[\frac{1-\chi^{J-s}}{1-\chi}\right] z_{G}^{\eta}\right]^{1 /(1-\eta)}>0 .
\end{aligned}
$$

\section{Computing moments}

Let $e_{\tau, j}(a ; \theta)$ denote the labor earnings, generated by the model, for an individual of ability $a$, age $j$ and who is 25 years old in calendar year $\tau$. Then

$$
\begin{aligned}
& E_{\tau, j}^{\mathrm{co}}(\theta)=\frac{1}{p_{\tau}(\theta)} \int_{a^{*}\left(w_{\tau}(\theta)\right)} e_{\tau, j}(a ; \theta) A^{\prime}(\theta) d a \\
& E_{\tau, j}^{\mathrm{hs}}(\theta)=\frac{1}{1-p_{\tau}(\theta)} \int_{0}^{a^{*}\left(w_{\tau}(\theta)\right)} e_{\tau, j}(a ; \theta) A^{\prime}(\theta) d a
\end{aligned}
$$

and

$$
\begin{aligned}
S_{\tau, j}^{\mathrm{co}}(\theta) & =\left(\frac{1}{p_{\tau}(\theta)} \int_{a^{*}\left(w_{\tau}(\theta)\right)}\left[e_{\tau, j}(a ; \theta)-E_{\tau, j}^{\mathrm{co}}(\theta)\right]^{2} A^{\prime}(\theta) d a\right)^{1 / 2} \\
S_{\tau, j}^{\mathrm{hs}}(\theta) & =\left(\frac{1}{1-p_{\tau}(\theta)} \int_{0}^{a^{*}\left(w_{\tau}(\theta)\right)}\left[e_{\tau, j}(a ; \theta)-E_{\tau, j}^{\mathrm{hs}}(\theta)\right]^{2} A^{\prime}(\theta) d a\right)^{1 / 2} .
\end{aligned}
$$




\section{References}

Ben-Porath, Yoram, "The Production of Human Capital and the Life-Cycle of Earnings," Journal of Political Economy, 1967, 75 (4), pp. 352-365.

Browning, Martin, Lars Peter Hansen, and James J. Heckman, "Micro Data and General Equilibrium Models," in John B. Taylor and Michael Woodford, eds., Handbook of Macroeconomics, Vol. 1A, Amsterdam: Elsevier, 1999, chapter 8, pp. 543-633.

Cordoba, Juan Carlos and Marla Ripoll, "What Explains Schooling Differences Across Countries?," Journal of Monetary Economics, March 2013, 60 (2), pp. 184-202.

Erosa, Andrés, Tatyana Koreshkova, and Diego Restuccia, "How Important Is Human Capital? A Quantitative Theory Assessment of World Income Inequality," Review of Economic Studies, October 2010, 77 (4), pp. 1421-1449.

Heckman, James J, Lance Lochner, and Christopher Taber, "Explaining rising wage inequality: Explorations with a dynamic general equilibrium model of labor earnings with heterogeneous agents," Review of economic dynamics, 1998, 1 (1), pp. 1-58.

Huggett, Mark, Gustavo Ventura, and Amir Yaron, "Human Capital and Earnings Distribution Dynamics," Journal of Monetary Economics, 2006, 53 (2), pp. 265-290.

_ , _ , and _ , "Sources of Lifetime Inequality," The American Economic Review, 2011, 101 (7), 2923-2954.

Keller, Elisa, "The Slowdown in American Educational Attainment," Journal of Economic Dynamics and Control, 2014, 46, pp. 252-270.

Manuelli, Rodolfo E. and Ananth Seshadri, "Human Capital and the Wealth of Nations," The American Economic Review, 2014, 104 (9), pp. 2736-62.

Restuccia, Diego and Guillaume Vandenbroucke, "A Century of Human Capital and Hours," Economic Inquiry, July 2013, 51 (3), pp. 1849-1866.

_ and _, "The Evolution of Education: A Macroeconomic Analysis," International Economic Review, August 2013, 54 (3), pp. 915-936. 
_ and _, "Explaining Educational Attainment across Countries and over Time," Review of Economic Dynamics, 2014, $17(4)$. 
Table 2: Calibrated Parameters

\begin{tabular}{ll}
\hline Ability distribution & $\mu=-0.87, \sigma=0.39$ \\
Initial human capital & $z_{H}=1.07$ \\
College technology & $\eta=0.44, z_{G}=1.24$ \\
On-the-job technology & $\phi=0.63, z_{F}=0.17$ \\
Wage per human capital & $g=1.005, w_{1940}=1.0$ \\
Life expectancy, college length & $J=50, s=4$ \\
Interest rate, depreciation & $r=1.05, \delta=0.0114$ \\
\hline
\end{tabular}

Table 3: Change in earnings growth between the 1940 and 1980 cohort (percent)

\begin{tabular}{lrrr}
\hline & All & High school & College \\
\hline Data & -43.3 & -58.6 & -33.9 \\
Model & -26.3 & -26.4 & -25.6 \\
Model/data & 60.8 & 45.0 & 75.3 \\
\hline
\end{tabular}

Source: IPUMS and Authors calculations.

Note: Earnings growth is measured by the ratio of earnings at age 55 to earnings at age 25, for a given cohort. This ratio, for example, fell by 43.3 percent for the average workers. The third column of this table is not an average of the first two columns. 


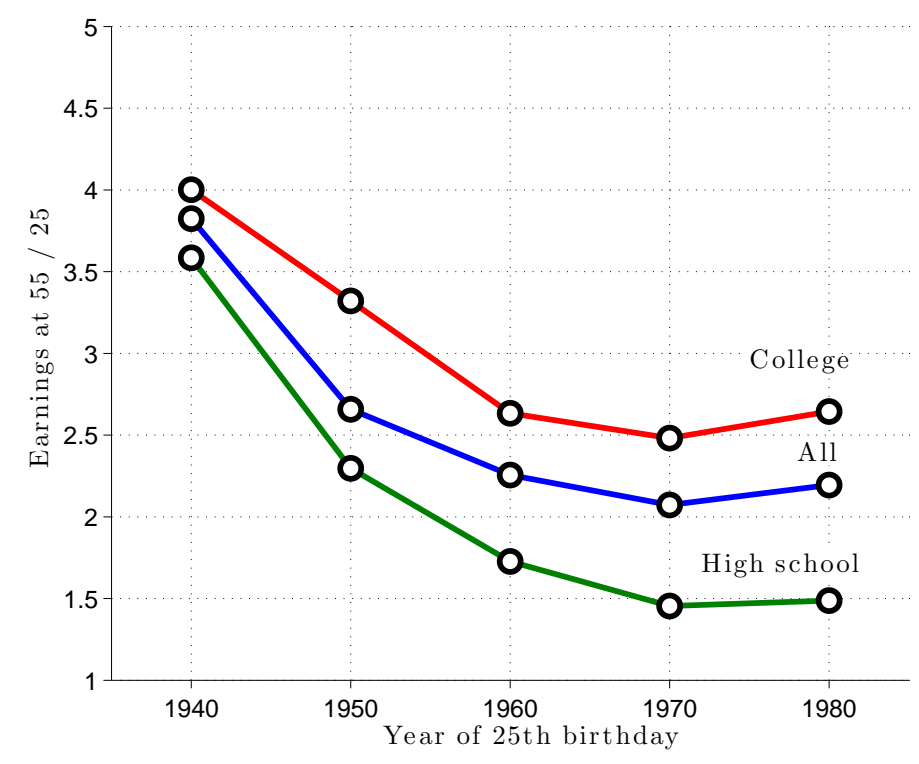

Figure 1: Growth in labor earnings from age 25 to 55 by cohort and educational attainment Source: IPUMS.

Note: The data is for employed white men, working for a wage.

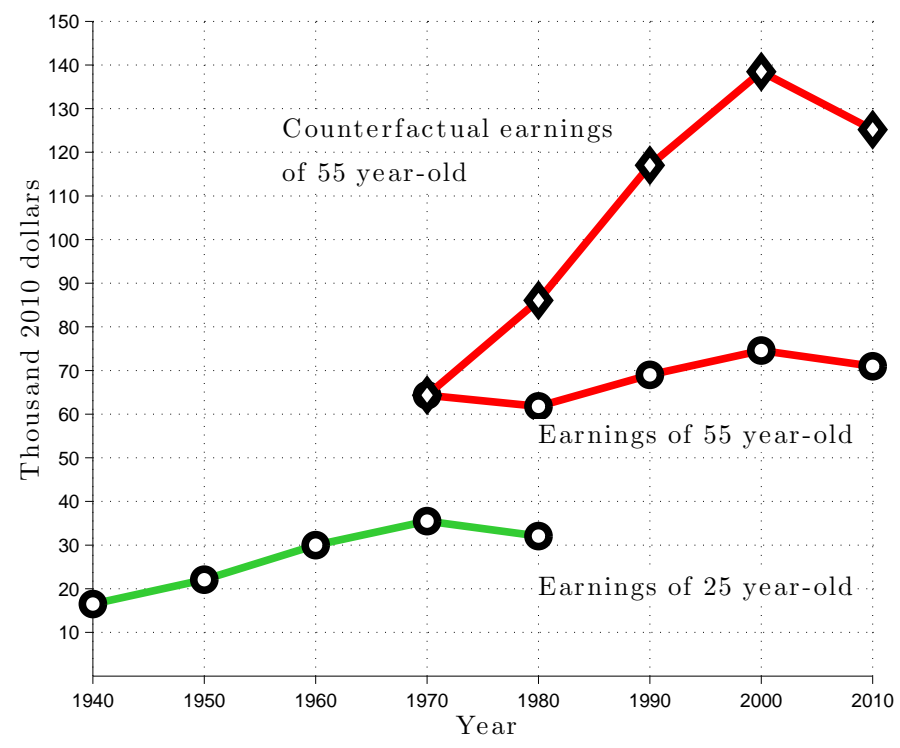

Figure 2: Earnings

Source: IPUMS and authors calculations.

Note: The counterfactual experiment assumes that the age-specific growth rate of earnings after age 25 for the 1940 cohort applies to each subsequent cohorts. 


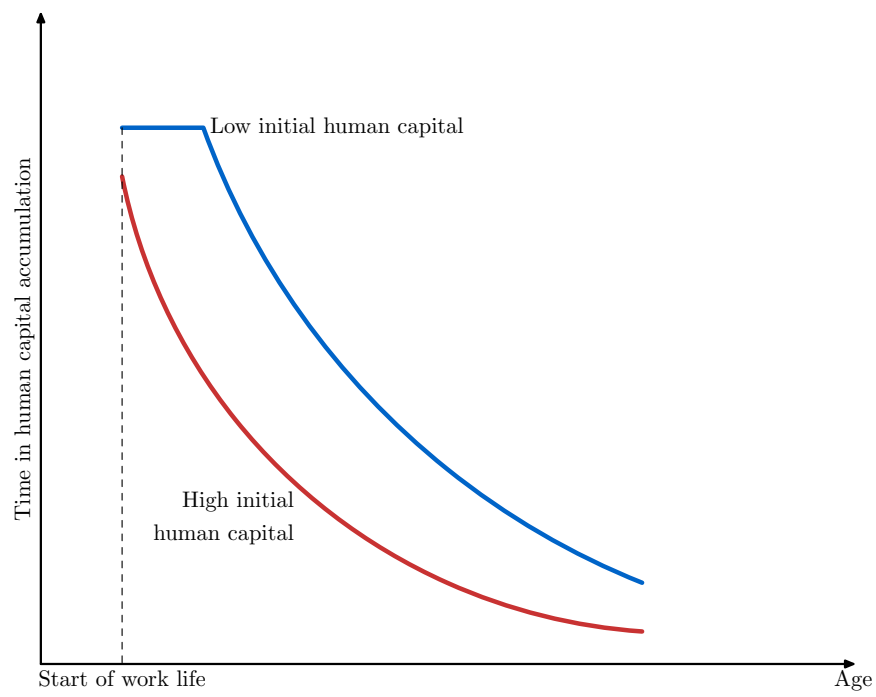

Figure 3: Typical path of time spent in human capital accumulation

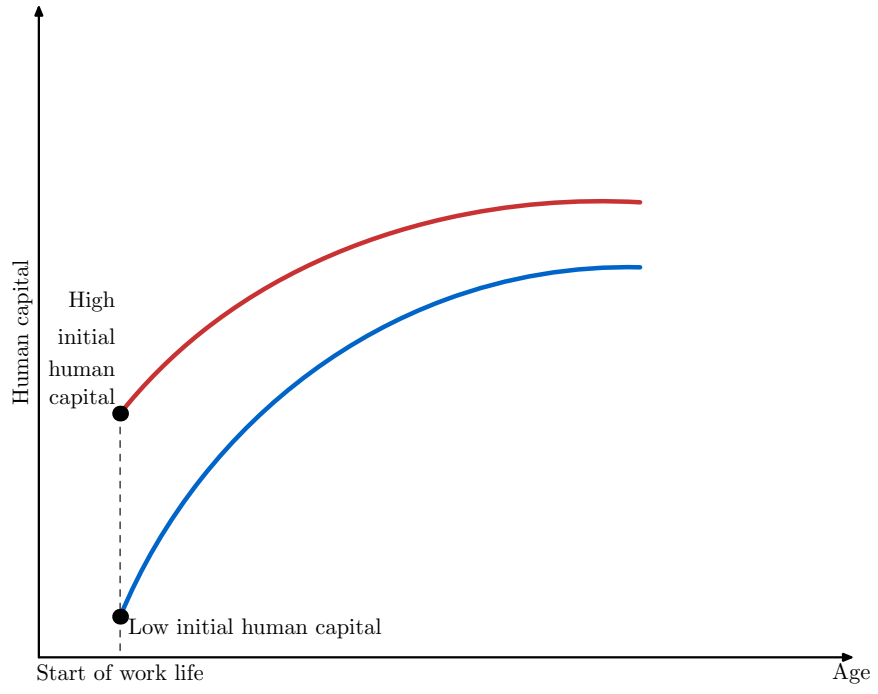

Figure 4: Typical path of human capital 

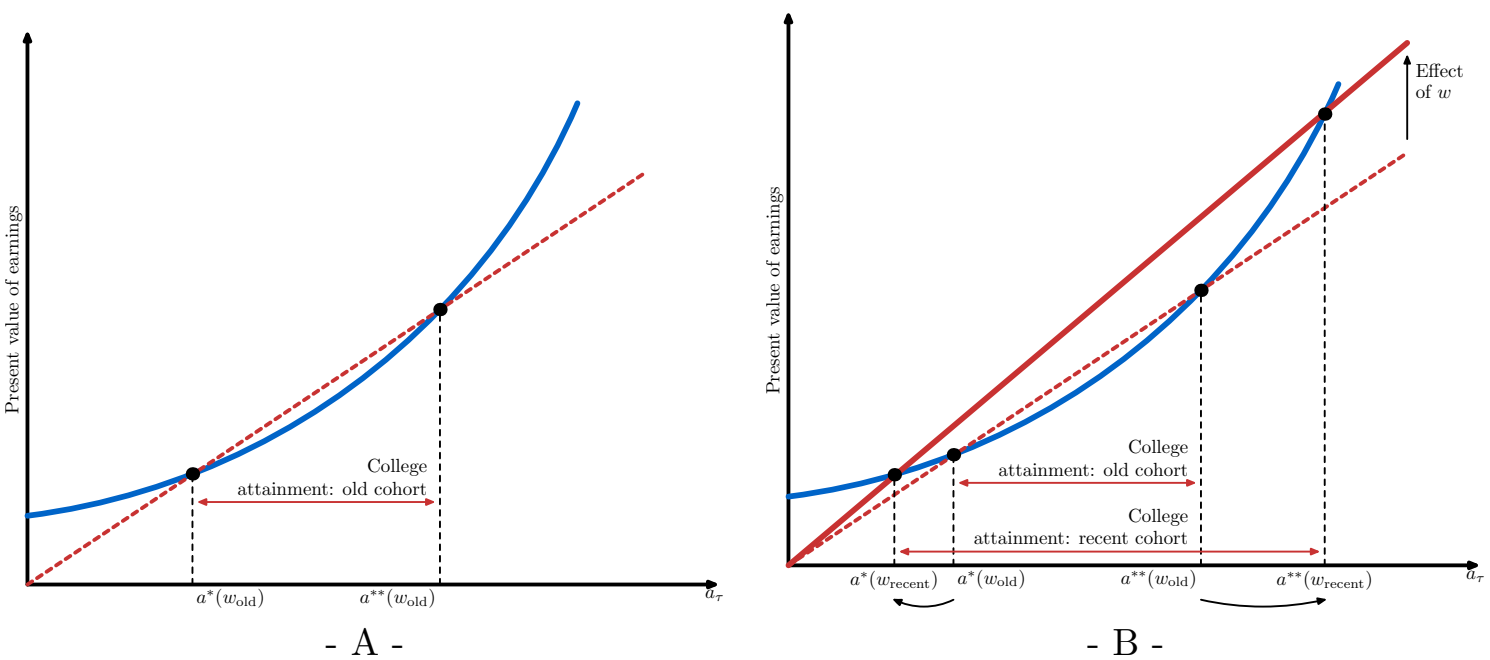

Figure 5: The determination of educational attainment, and the effect of productivity growth

Note: Panel A illustrates the determination of educational attainment for a cohort facing productivity $w_{\text {old }}$ at the start of its life. The convex line represents the left-hand side of Equation (14) while the straight line represents the right-hand side. Panel B illustrates the effect of an increase in productivity from $w_{\text {old }}$ to $w_{\text {recent }}$ : only the right-hand side of Equation (14) increases, leading to an increase in educational attainment.

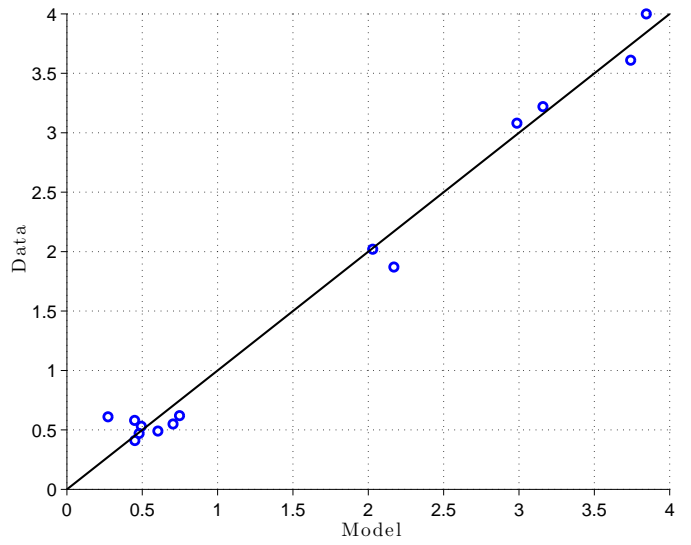

- A -

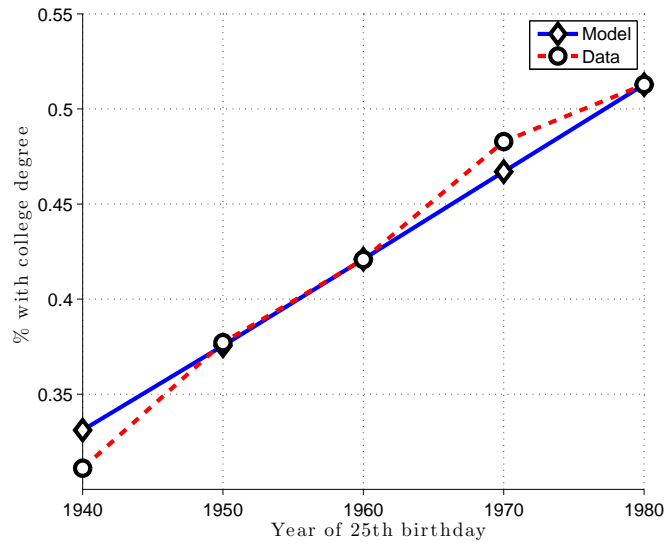

- B -

Figure 6: The model's fit

Note: Panel A shows the model's fit to the statistics of earnings growth and dispersion pertaining to the 1940 cohort -the first two parts of problem (15). Namely, each point represents either a measure of earnings growth or a measure of dispersion at various age, for the 1940 cohort. Panel B shows the model's fit to the trend in educational attainment -the last part of problem (15). 


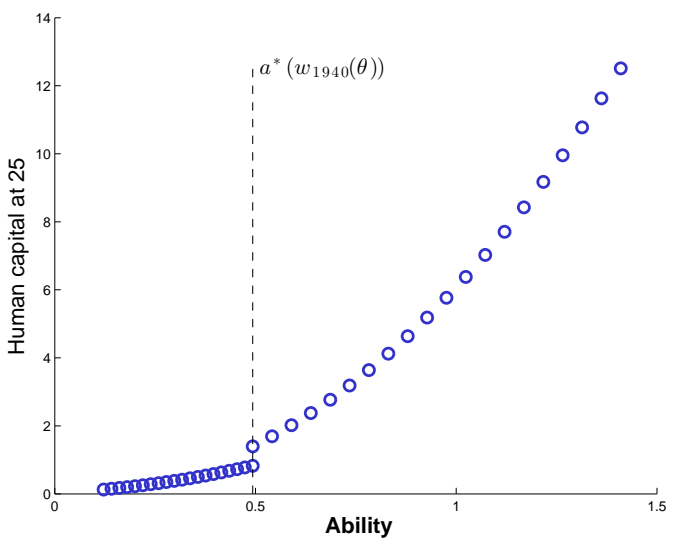

- A -

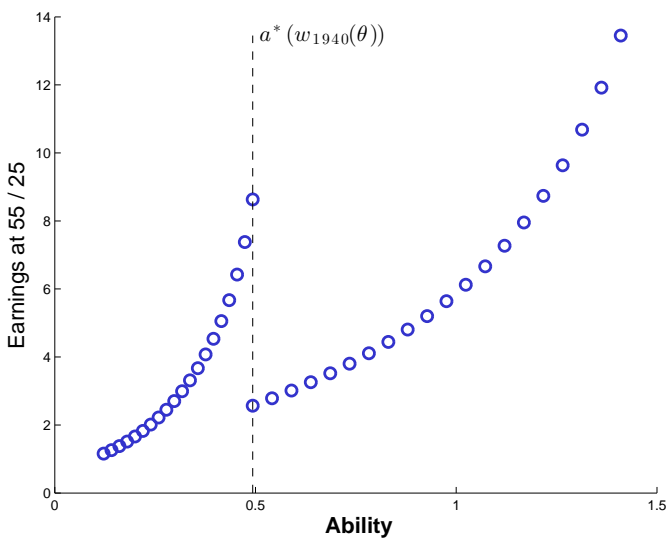

$-\mathrm{C}-$

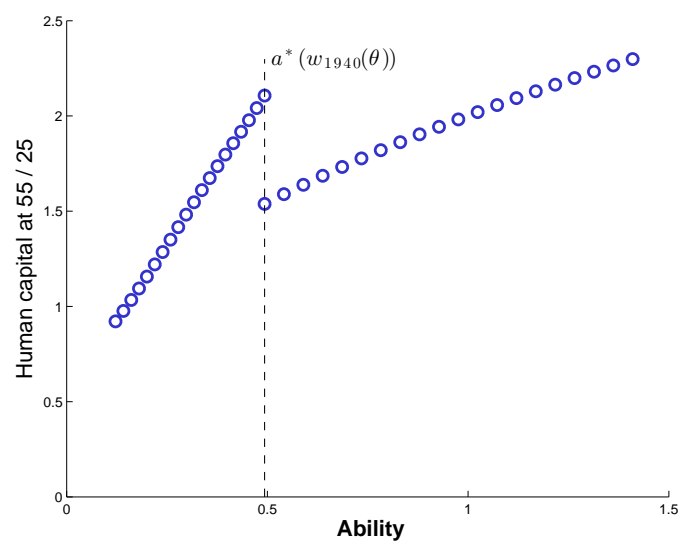

$-\mathrm{B}$ -

Figure 7: The effect of ability on the life cycle profile of human capital and earnings growth

Note: Panel A shows the level of human capital at age 25, for each ability level. Panel B shows the ratio of human capital at age 55 versus age 25. Panel $\mathrm{C}$ shows the ratio of earnings at age 55 versus 25 . The parameters used to construct these figures are in Table 2. The ability range covers 99.8 percent of the domain of $a$. 


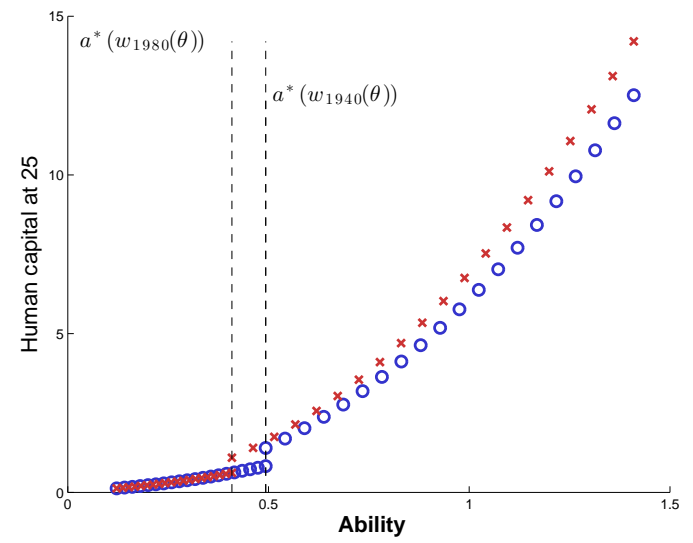

- A -
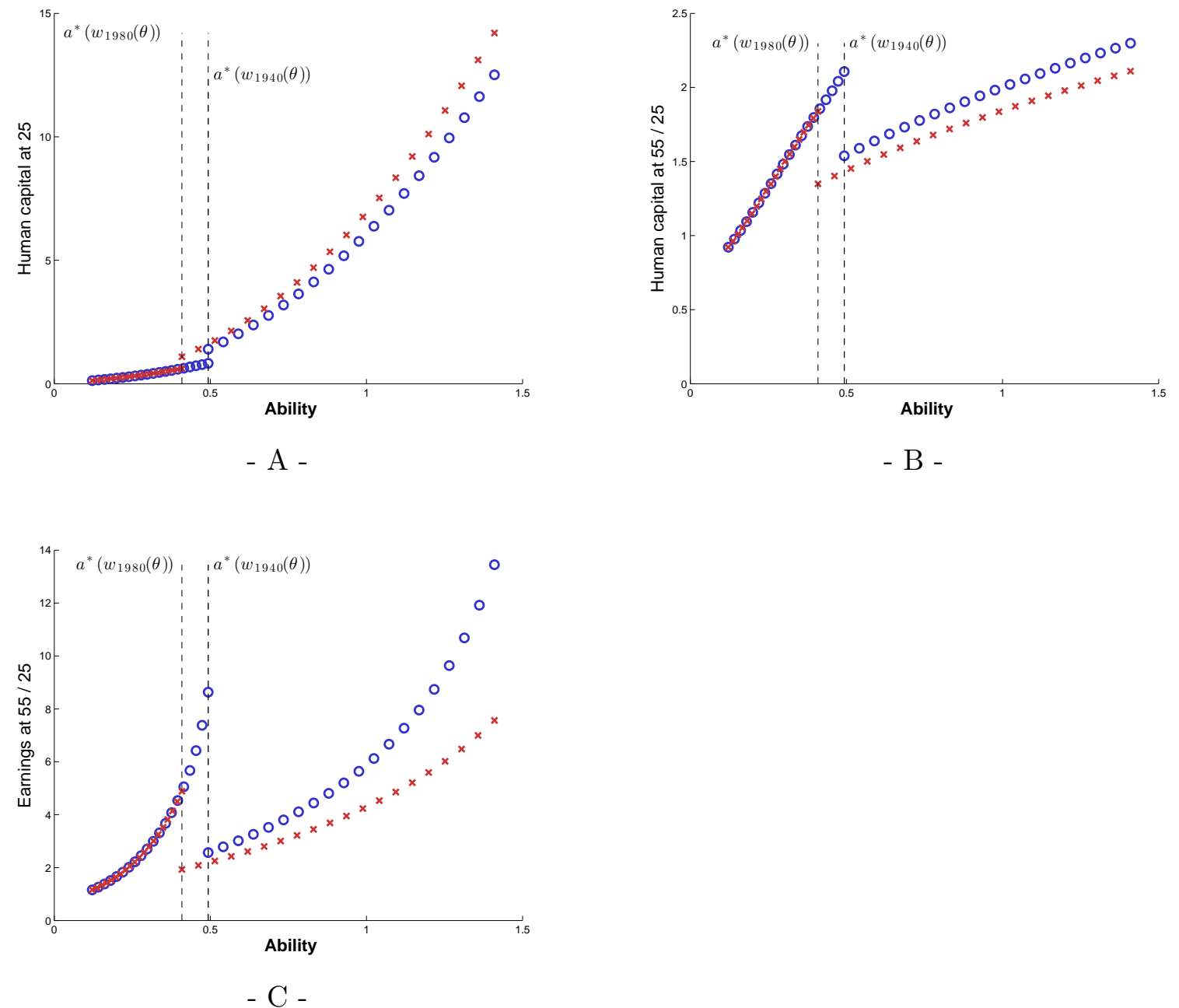

Figure 8: The effect of productivity on the life cycle profile of human capital and earnings growth

Note: The blue 'o' denote the 1940 cohort, the red ' $\mathrm{x}$ ' the 1980 cohort. Panel A shows the level of human capital at age 25, for each ability level. Panel B shows the ratio of human capital at age 55 versus age 25. Panel C shows the ratio of earnings at age 55 versus 25 . The parameters used to construct these figures are in Table 2 . The ability range covers 99.8 percent of the domain of $a$. 

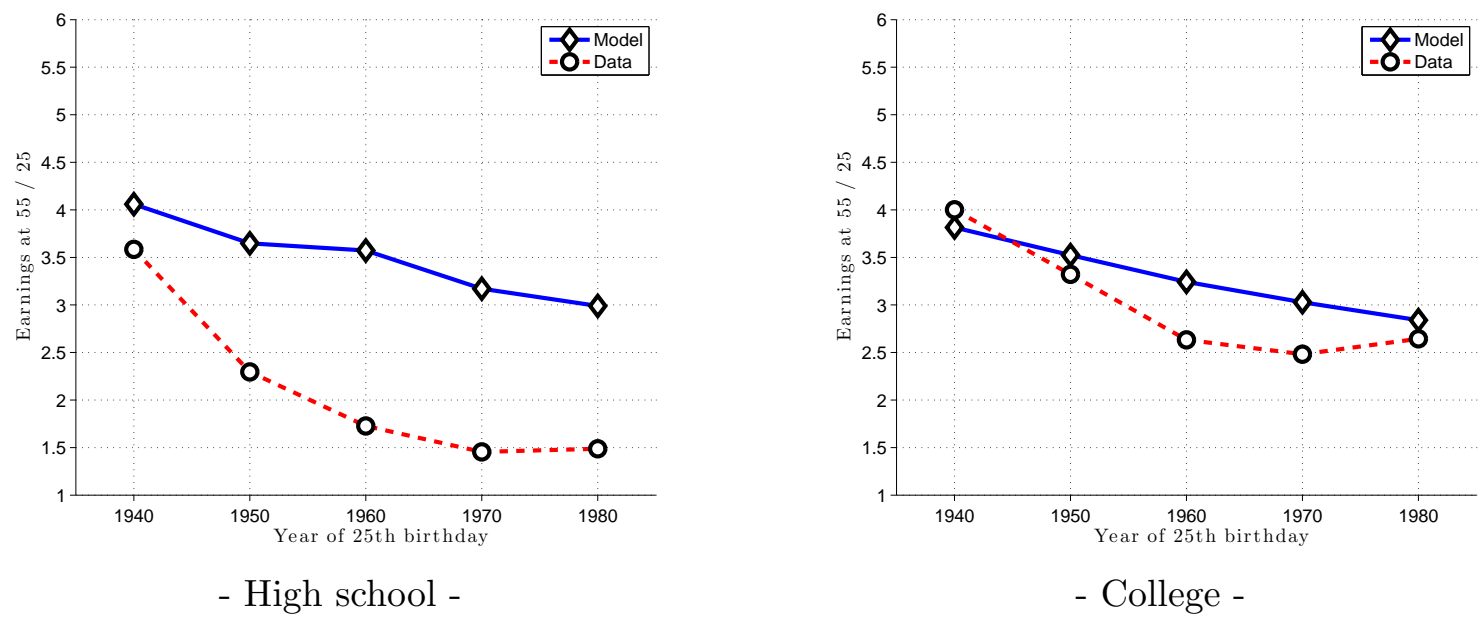

- College -

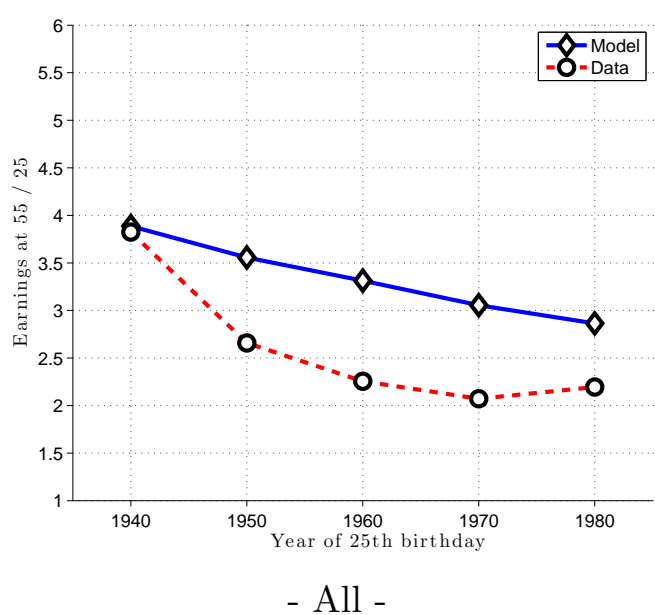

Figure 9: Growth in labor earnings from age 25 to 55 by cohort and educational attainment: model and data

Source: IPUMS and authors calculations. 